\title{
Work Engagement and its Relationship with State and Trait Trust: A Conceptual Analysis
}

\author{
Aamir Ali Chughtai \\ Finian Buckley \\ Dublin City University Business School, Ireland
}

\begin{abstract}
The main objective of this paper is to highlight the vital role that both state trust (trust in top management, trust in immediate supervisor and trust in co-workers) and trait trust or trust propensity play in the advancement of employee work engagement. This study posits that the relationship between trust and work engagement is mutually reinforcing and leads to an upward spiral effect. That is, high levels of state and trait trust boost work engagement, which in turn augments both forms of trust and so on. Additionally, the current paper also examines the interaction effects of state and trait trust on employees' work engagement.
\end{abstract}

\section{Introduction}

In the past, psychology has predominantly concentrated on the negative aspects of human behaviour such as malfunctioning, weakness and pathology (Schaufeli and Salanova, 2007). However, recently there has been a growing interest in positive psychology, which instead of focussing on human weaknesses, lays emphasis on human strengths, optimal functioning and well being (Seligman and Csikszentmihalyi, 2000). This trend towards positive psychology has led to the emergence of the concept of work engagement.

\section{What is Work Engagement?}

Work engagement is conceptualised as the positive antipode of workplace burnout (Schaufeli and Bakker, 2004), a syndrome characterised by mental or physical exhaustion, cynicism and reduced professional efficacy (Maslach, Jackson and Leiter, 1996). In the literature, there are two approaches to work engagement. The first approach is advocated by Maslach and Leiter (1997). Maslach and Leiter (1997) argue that engagement is characterised by energy, involvement and efficacy - the direct opposites of the three dimensions of burnout. These researchers further contend that when individuals experience the feeling of burnout 'energy turns into exhaustion, involvement turns into cynicism and efficacy turns into ineffectiveness' (p. 24). According to this conceptualisation, engagement is measured by the reverse pattern of scores on the Maslach Burnout Inventory-General Survey (MBI-GS) dimensions (Maslach, Schaufeli, and Leiter, 2001). This means that low scores on exhaustion and cynicism and high scores on professional efficacy are indicators of engagement.

Some empirical support for this conceptualization of engagement is provided by case studies of two hospital units (Maslach and Leiter, 1997). The employees in one unit displayed a typical burnout profile (i.e. high scores on exhaustion and cynicism and 
low scores on efficacy) whereas employees in the other unit had an opposite profile of engagement (i.e. low scores on exhaustion and cynicism and high scores on professional efficacy).

The second approach to work engagement has been put forward by Schaufeli, Salanova, Gonzalez-Roma and Bakker (2002). These researchers point out that Maslach and Lieter's (1997) conceptualisation of work engagement prohibits an examination of the relationship between burnout and engagement since both constructs are viewed as opposite poles of a continuum and are assessed with the same instrument (the MBI-GS). Schaufeli and his co-researchers (2002) argue that burnout and work engagement are two distinct albeit negatively correlated states of mind as opposed to being two opposite ends of a single continuum, and as a result they define work engagement in its own right as a 'positive, fulfilling work related state of mind that is characterised by vigour, dedication and absorption' (Schaufeli et. al., 2002, p. 74). Vigour reflects the readiness to devote effort in one's work, an exhibition of high levels of energy while working and the tendency to remain resolute in the face of task difficulty or failure. Dedication refers to a strong identification with one's work and encompasses feelings of enthusiasm, inspiration, pride, and challenge. The third dimension of engagement is absorption. Absorption is characterised by being completely immersed in one's work, in a manner that time appears to pass rapidly and one finds it difficult to disengage oneself from work. Several studies have empirically validated the three factor structure proposed by the recently developed questionnaire to measure engagement, the Utrecht Work Engagement Scale (UWES) (e.g. (Schaufeli et. al., 2002; Schaufeli and Bakker, 2004; Schaufeli, Taris and Rhenen, 2008).

In the present paper we adopt the definition of work engagement advocated by Schaufeli and his colleagues (2002) because of the following four reasons. First, this definition separates work engagement from the related concept of burnout and as a result establishes it as an independent construct which is important in its own right.

Second, Schaufeli et. al's definition encompasses both the affective and cognitive aspects of work engagement. This implies that in addition to cognitions, engagement also involves an active utilization of emotions and feelings (Salanova and Schaufeli, 2008).

Third, as mentioned above, this definition splits engagement into three dimensions: (1) vigour; (2) dedication; and (3) absorption, which can be analysed separately. This permits for a more accurate detection of where strengths and deficiencies exist in terms of each facet of work engagement (Freeney and Tiernan, 2006).

Finally, the three dimensions of work engagement specified by Schaufeli et. al. (2002) can be empirically measured by a psychometrically valid questionnaire, that is, the Utrecht Work Engagement Scale.

The driving force behind the importance of work engagement is that it has positive consequences for the organization. For example, empirical research on work engagement reports that high levels of engagement lead to enhanced organizational commitment, increased job satisfaction, lower absenteeism and turnover rates, improved health and well being, more extra role behaviours, higher performance and 
a greater exhibition of personal initiative, proactive behaviour and learning motivation (Schaufeli and Salanova, 2007). Thus investing in conditions, which foster work engagement among employees, is vital for the growth and profitability of organizations.

\section{Job Demands - Resources Model}

Work engagement has been mostly analysed within the framework of the job demands-resources model. The basic premise of this model is that employees may work in different work environments but the characteristics of these work environments can be classified into two broad categories: (1) job demands; and (2) job resources (Demerouti, Bakker, Nachreiner and Schaufeli, 2001; Bakker and Demerouti, 2007). The job demands-resources model is basically based on two main propositions (Bakker and Demerouti, 2007). The first proposition of this model states that burnout and engagement may be notably influenced by job demands and job resources (Demerouti, Bakker, Nachreiner and Schaufeli, 2001; Bakker and Demerouti, 2007). Job demands are those aspects of the job that require intense physical or mental effort and are therefore linked with certain physiological and / or psychological costs (Demerouti, Bakker, Nachreiner and Schaufeli, 2001; Bakker and Demerouti, 2007). Examples are: high work pressure, an unfavourable physical environment and emotionally demanding interaction with clients (Bakker and Demerouti, 2007).

Job resources in contrast are those features of the job that (a) are instrumental in attaining work-related goals (b) decrease job demands and the physiological and psychological costs linked to these demands, and (c) cultivate personal growth and development (Bakker and Demerouti, 2007). Examples of job resources include job control, performance feedback, social support and supervisory coaching (Schaufeli and Salanova, 2007).

The second proposition of this model suggests that job demands and job resources bring forth two psychological processes, which result in the development of burnout and engagement. The first is the health impairment process, which begins with persistent job demands, which may diminish employees' energy resources and may thus lead to burnout and weakening of health (Hakanen, Bakker and Schaufeli, 2006).

The second psychological process proposed by the JD-R model is the motivational process which starts with the availability of job resources and is likely to lead to work engagement and positive outcomes such as greater organizational commitment and enhanced job performance (Salanova, Agut and Peiro, 2005).

Job resources such as social support, coaching or performance feedback may play either an intrinsic or an extrinsic motivational role (Bakker and Demerouti, 2007). As intrinsic motivators, job resources, by fulfilling basic human needs such as the needs for competence, belongingness and autonomy cultivate individuals' growth and development (Deci and Ryan, 1985). For instance effective training and development strategies increase job competence whereas job control and social support satisfies the need for autonomy and the need to belong, respectively. As extrinsic motivators job resources inspire employees to exert effort in their work and as a result increase 
the chances that the employees will be able to complete their tasks successfully and consequently attain their work goals (Schaufeli and Bakker, 2004; Bakker and Demerouti, 2007). In both cases, it is likely that the availability of job resources augments employees' work engagement, whereas their absence may obstruct goal accomplishment and as a result breed feelings of frustration and failure (Bakker and Demerouti, 2007).

More recently, Xanthopoulou et. al. (2007) have expanded the job demandsresources model by incorporating personal resources into the model. They found that three personal resources, namely, self efficacy, organization based self esteem and optimism were significantly related to work engagement. More specifically, the results of the structural equation modelling showed that as hypothesised, personal resources partially mediated the effects of job resources (autonomy, social support and opportunities for professional development) on work engagement suggesting that job resources promote the development of personal resources which in turn augment employees' work engagement.

\section{The Role of Trust in Work Engagement}

Previous research indicates that job resources are the most important predictors of work engagement (Schaufeli and Bakker, 2004). For instance work engagement has been found to be positively related to job resources such as social support from coworkers and superiors, performance feedback, coaching, job control, task variety and training facilities (Schaufeli and Salanova, 2007). The fact that work engagement has been primarily articulated as a function of job resources is not surprising because most of the empirical research on the antecedents of work engagement revolves around the job demands-resources model. As a result the relationship between work engagement and variables other than job resources has received scant empirical attention. Thus there is a growing need to examine the impact of other personality, psychological and situational variables on engagement in order to gain a better understanding of this construct.

To fill this gap, the present paper endeavours to examine the effects of trust on employees' work engagement. More specifically, the central aim of this paper is to conceptually analyse the impact of both state and trait trust on work engagement. State or situational trust originates from one person's assessment of the trustworthiness of a specific other individual (McAllister, 1995; Mishra, 1996; McKnight, Cummings and Chervany, 1998). The current paper focuses on three foci of state trust, namely the top management, immediate supervisor and co-workers. Thus state trust in the context of the present study refers to an individual's perception of the trustworthiness of the top management, his or her immediate supervisor and co-workers.

In contrast, trait trust or trust propensity is a relatively stable individual difference variable (Rotter, 1980) that represents an individual's dispositional tendency to trust or distrust other individuals. Mooradian, Renzl and Matzler, (2006) argue that trust propensity is "neither focussed on specific others, nor dependent on specific contexts and it is not only related to lifetime experiences but also to temperament, and thereby to genetics and bio-physiological structure", (p. 525). 
The present study suggests that the relationship between the two forms of trust and work engagement is mutually reinforcing overtime. More specifically, this study proposes an upward spiral effect: high levels of trust in top management, immediate supervisor and co-workers and a high tendency to trust others boosts work engagement, which subsequently increases trust at all three levels of the organizational hierarchy by positively affecting an individual's propensity to trust. In addition, the present analysis also examines the interaction effects of state and trait trust on work engagement.

No published study to date has empirically or conceptually examined the relationship between trust and work engagement. This paper extends the developing engagement literature by analyzing how each form of trust influences employee work engagement and how these influences can become a virtuous cycle. In short, this study argues that work engagement is not only a function of environmental factors like job resources but can also be induced by psychological variables such as trust.

The rest of the article is organized as follows. The next section looks at the definition of state or situational trust, examines the nature of the three situational forms of trust, (trust in top management, trust in immediate supervisor and trust in co-workers) and explains the concept of trust propensity or trait trust. In the following section we present our research model, which exhibits how work engagement and trust influence each other. On the basis of this model we then develop a series of conceptual propositions. The paper finally concludes with a discussion on the implications of this research for the managers and their organizations.

\section{State or Situational Trust}

Research evidence indicates that a climate of trust leads to wide and diverse benefits for individuals, teams and organizations. A plethora of studies have demonstrated how increases in trust result directly or indirectly in more positive workplace behaviours and attitudes (Dirks and Ferrin, 2002), better team processes (Jones and George, 1998) and superior levels of performance (Dirks, 2000).

Although there is widespread agreement among scholars concerning the importance of trust in the smooth functioning of organizations, there is surprisingly no concurrence on the definition of trust. In his comprehensive review Kramer (1999, p. 571) concluded that "a concise and universally accepted definition of trust [has] remained elusive". One of the most widely cited definitions of trust is given by Mayer, Davis and Schoorman (1995). They define trust as "the willingness of a party to be vulnerable to the actions of another party based on the expectation that the other will perform a particular action important to the trustor, irrespective of the ability to monitor or control the other party", (Mayer et. al., 1995, p. 712). In a similar vein, Rousseau, Sitkin, Burt and Camerer (1998) suggest that trust is "a psychological state comprising the intention to accept vulnerability based upon positive expectations of the intentions or behaviour of another" (1998, p. 395). Some scholars on the other hand, endeavour to capture the intricacies of trust with explicitly multidimensional definitions which highlight the different aspects of a trusting relationship (e.g. Cummings and Bromily, 1996; Mishra, 1996; Tschannen-Moran and Hoy, 2000). These definitions reflect the willingness of the trustor to depend on the trustee after having taken into consideration the personal characteristics of the trustee (McKnight 
and Chervany, 2001). For example, Cummings and Bromily (1996) define trust as "an individual's belief or a common belief among a group of individuals that another individual or group (a) makes good-faith efforts to behave in accordance with any commitments both explicit and implicit, (b) is honest in whatever negotiations preceded such commitments, and (c) does not take excessive advantage of another even when the opportunity is available" (p. 303).

While trust has been defined and conceptualized in many different ways, there are two essential elements, which are common across most definitions: (1) positive expectations and (2) willingness to accept vulnerability (Lewicki, Tomlinson and Gillespie, 2006). Positive expectations are positive beliefs held by the trustor that the trustee will act in a way that is consistent with his or her welfare. Vulnerability on the other hand, can be envisaged as risk of possible loss and implies that the trustor is prepared to take a risk by placing his or her welfare in the hands of the trustee.

For the purpose of the current paper we adopt the multi-dimensional view of trust and consequently define it as "one party's willingness to be vulnerable to another party based on the belief that the latter party is (a) competent, (b) reliable, (c) open and (d) concerned", (Mishra, 1996, p. 265). Other scholars also acknowledge that the four dimensions of trustworthiness specified by Mishra (1996) appear most frequently in the literature and explain a major portion of perceptions of trustworthiness (Clark and Payne, 1997; Ellis and Shockley-Zalabak, 2001; Dietz and Den Hartog, 2006).

Competence refers to the knowledge and capabilities of the trustee (Butler and Cantrell, 1984); openness implies that there is a free flow of information and ideas (Tschannen-Moran and Hoy, 2000); concern refers to trustor's belief that the trustee will not behave opportunistically and as a result will care about his or her best interests (Mishra, 1996); and reliability reflects promise fulfilment (Mishra, 1996; Shockley-Zalabak, Ellis and Winograd, 2000).

One benefit of the multidimensional view of trust is that it can augment the understanding of working relationships (Smith and Barclay, 1997). For example, it is quite probable, that employees may perceive the organizational leaders or their coworkers to be trustworthy in some domain such as competence but not in others such as integrity. An insight into where trust is wanting in the relationship can help focus corrective action. This advantage is lost with a one-dimensional conceptualization of trust (Smith and Barclay, 1997).

Mishra (1996) argues that the four dimensions of trust, namely, competence, concern, reliability and openness, represent components of an overall trust construct. He further contends that these dimensions amalgamate in a multiplicative way to create the overall degree of trust that the trustor has with respect to a particular party. This means that "a low level of trust in terms of any of the dimensions off sets high levels of trust in terms of other dimensions" (1996, p. 269).

As mentioned above the present research focuses on three foci of state trust, namely, the top management, immediate supervisor and co-workers. Thus state trust in the current paper reflects an individual's willingness to rely on the top management, his or her immediate supervisor and co-workers based on the belief 
that these referents are (1) competent; (2) reliable; (3) open; and (4) concerned. The nature of each situational form of trust is discussed next.

\section{Forms of State or Situational Trust}

\section{$\underline{\text { Trust in Top Management }}$}

Top management refers to the group of persons at or near the top of the organizational chart (McCauley and Khunert, 1992). The trust between top management and their employees is not interpersonal in nature, but is rather seen as originating from the structured relations, roles and the rules of the organization. According to McCauley and Khunert (1992), as a means of assessing the extent to which they could trust the management, the employees persistently monitor the organizational environment. Employees will reciprocate trust relations communicated by management only if the organizational structures, roles and climate reflect a trustworthy system. Alternatively, if they represent a lack of trust in employees by top management, employees will react with a similar lack of trust.

\section{Trust in Immediate Supervisor and Trust in Co-workers}

As opposed to trust in top management, which is more impersonal (i.e. less dyadic) in nature, trust in supervisor and trust in co-workers highlights an interpersonal or dyadic form of trust (Costigan, Ilter and Berman, 1998), which emanates from the assessment of personal characteristics and behaviour of these referents.

Traditionally studies have focused mainly on supervisory trust (Costigan, Ilter and Berman, 1998; Elis and Shockley-Zalabak, 2001). More recently, however, trust in co-workers has gained more significance because of the extensive movement towards self-managed work teams. The success of self-managed teams is contingent on cooperation and teamwork, and research evidence indicates that trust in peers can play a crucial role in fostering interpersonal cooperation and in developing effective team relationships (Jones and George, 1998).

All three forms of situational trust can have vital consequences for the organization. More specifically, trust in leadership (i.e. top management and immediate supervisor) is likely to result in positive outcomes directed towards the supervisor (such as job performance) and the organization (such as organizational commitment); whereas, trust in co-workers might lead to positive outcomes for the co-workers such as sharing information with co-workers and helping co-workers in need of assistance (Dirks and Skarlicki, 2004).

\section{Trait Trust or Propensity to Trust}

Trust propensity or trait trust is commonly viewed as the general willingness to trust others (Mayer et. al., 1995). Rotter (1980) argues that people differ in their propensity to trust others. Life experiences, personality types, cultural background, education and several other socio-economic factors determine one's propensity to trust (Mayer et. al., 1995). Individuals with a high propensity to trust believe that most people are sincere, fair and have good intentions (Mooradian et. al., 2006). In contrast, people who have a low propensity to trust, see others as self-centred, 
conniving and potentially dangerous (Mooradian et. al., 2006). McKnight et. al., (1998) argue that trust propensity has recently acquired more importance because cross functional teams, structural re-organizations and joint ventures create new working relationships more frequently. This is because an individual's trust propensity is likely to be the most significant trust precursor in novel, uncertain or unstructured situations prior to the availability of information about the trustee (Rotter, 1980; Mayer et. al., 1995; Bigley and Pierce, 1998).

\section{The Relationship between Work Engagement and Trust}

The relationship between work engagement and the two forms of trust, that is, state and trait trust is depicted by the following model:

Figure 1. The Relationship between Trust and Work Engagement

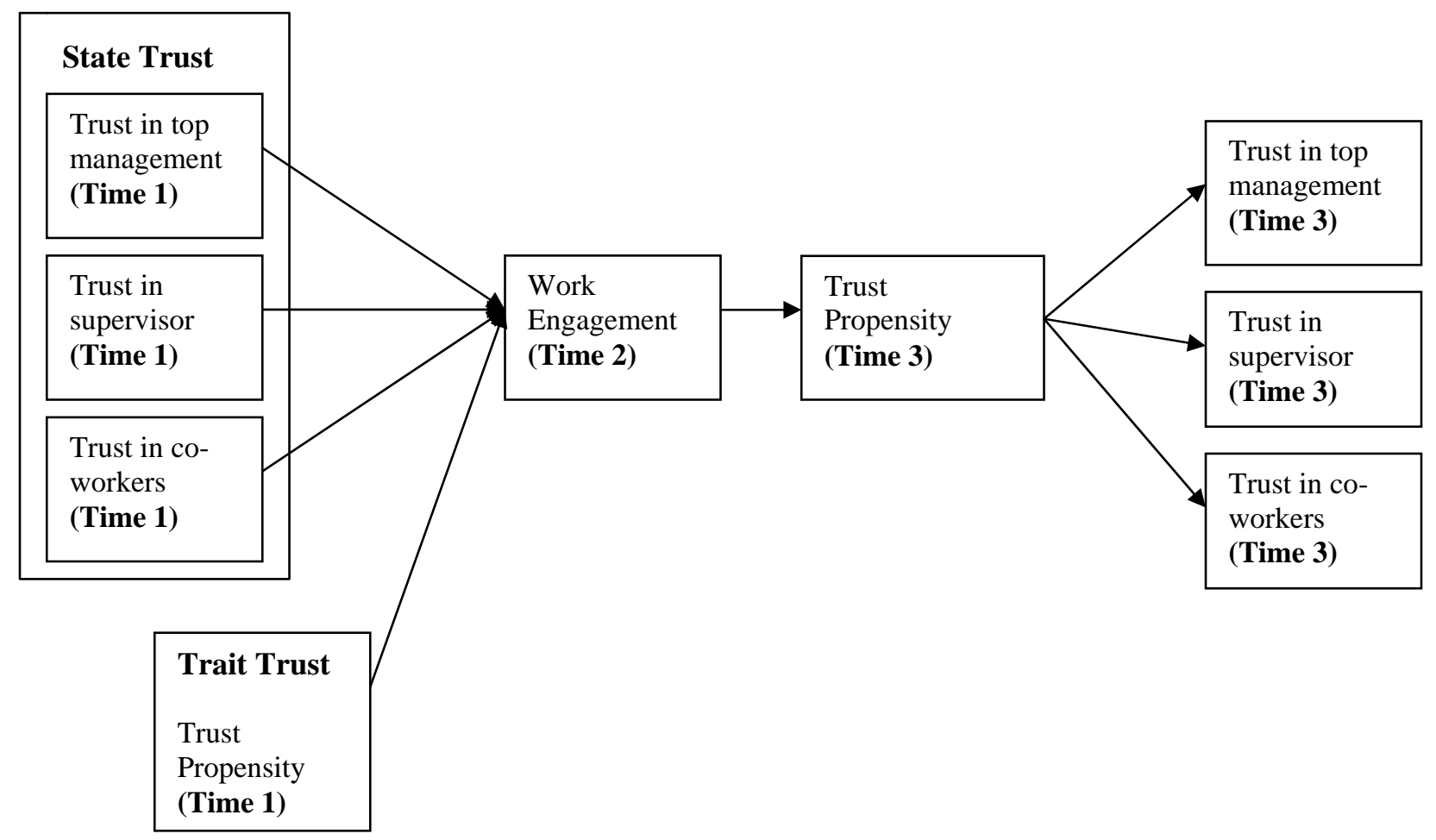

The first part of the model presented in figure 1 argues that positive trust in the top management, immediate supervisor and co-workers in terms of Mishra's (1996) four factors of trustworthiness (i.e. competence, openness, concern and reliability) and a high propensity to trust others at Time 1 would increase work engagement at Time 2 . The second part of this model suggests that enhanced levels of work engagement at Time 2 would subsequently increase trust in all three referents through the mediating mechanism of trust propensity at Time 3. In other words this model proposes that the relationship between trust and work engagement is mutually reinforcing over time 
and leads to an upward spiral effect. That is high trust promotes work engagement, which in turn boosts trust and so on.

First the relationship between the three situational forms of trust and work engagement will be analyzed. This will be followed by an analysis of how trust propensity can induce work engagement. Finally this section will examine how work engagement in turn can influence trust at each level of the organizational hierarchy by positively influencing trust propensity.

\section{Relationship between the Three Situational Forms of Trust and Work Engagement}

\section{Work Engagement and Trust in Top Management}

The first dimension in Mishra's model is competence. When employees recognise that the top management has the skilful insight and ability to augment the growth and productivity of the organization by making competent decisions, it would give them increased assurance of a more profitable future with the organization (Spreitzer and Mishra, 2002). In such a situation employees are bound to concentrate on the work that needs to be done, rather than feel concerned about such issues as the sustainability of their future employment (Mayer and Gavin, 2005). Complete focus and concentration on job tasks, in turn, may transform into work engagement (Kahn, 1990; May et. al., 2004). As opposed to this, if the employees perceive top management as ineffectual and strongly feel that under them the organization has a bleak future they would invariably become pessimistic about their own future in the organization. Consequently, they are likely to experience a sense of uncertainty, stress and apprehension, which in turn can result in disengagement from work.

The reliability aspect of trust postulates that the top management will deliver on their promises. However, if the employees realise that the top management has been unsuccessful in fulfilling its promised inducements, it would lead to a loss of trust and would tantamount to a breach of the psychological contract (Robinson, 1996). An infringement or violation of the psychological contract surfaces when one party in a relationship recognises another to have failed to execute promised commitments (Robinson and Rousseau, 1994). When employees experience a contract violation, their sense of fulfilment with both the job and the organization is bound to diminish (Robinson and Rousseau, 1994). It may become increasingly difficult for employees to feel encouraged enough to perform satisfactorily when they can no longer rely on promised incentives (Robinson and Rousseau, 1994). In such circumstances employees are likely to disengage from work (Schaufeli and Salanova, 2007). Hence, in order to develop and cultivate work engagement it is vital that the top management delivers on its promises and endeavours to create a suitable psychological contract, which should depict an "optimal fit" between the employee and the organization in terms of common expectations (Schaufeli and Salanova, 2007).

Openness is the approach through which the top management can ensure a free flow of communication with their employees; this is achieved by not withholding vital information that is essential for building trust between the two. When employees believe that the top management is communicating organizational issues candidly, it 
reduces insecurity or uncertainty amongst them (Mishra and Sprietzer, 1998). This is because such vital information gives the employees a clearer idea about the aims and motives of the top managers. Such practice would ensure that employees would be able to freely focus on working towards achieving their work related goals rather than being constantly preoccupied by feelings of mistrust and doubt. Being 'fully there' psychologically when at one's job and being totally absorbed in one's work activities in turn should invariably lead to enhanced work engagement (Kahn, 1990; Rothbard, 2001).

Furthermore, such open access to information pertaining to the mission of an organization helps to build a stronger sense of meaning and purpose for the employees by equipping them with a greater understanding of how their own work can contribute to the organizational aims and objectives (Sprietzer, 1996). When employees experience a sense of meaningfulness and purpose in their job, their work motivation is likely to strengthen which may consequently result in greater work engagement (May et. al., 2004).

In contrast to this open work environment, the top management's decision to conceal key organisational information and keep employees in the dark would obviously promote feelings of suspicion, anxiety and insecurity, which could result in disengagement from work.

Concern is the fourth and final dimension in Mishra's model. The top management's understanding and concern for their employees, is clearly mirrored by the policies and procedures carried out by them. It is suggested that based on the norm of reciprocity in social exchange (Blau, 1964), when employees recognize that policies and procedures adopted by top managers are clearly focused towards promoting and enhancing their well being, they are more likely to repay the organization with higher and stronger levels of work engagement (Saks, 2006). Saks (2006) suggests that immersing oneself more completely into one's work roles and dedicating greater amounts of cognitive, emotional and physical resources to one's job is a very insightful manner for individuals to respond to the resources and rewards provided by their organization.

In view of the preceding discussion the following proposition is formulated:

Proposition 1: High trust in top management at Time 1 would increase employees' work engagement at Time 2.

\section{Work Engagement and Trust in Immediate Supervisor}

There can be an increase in work engagement amongst employees if there is a sound sense of trust in the competence and capability of the immediate supervisor. If the employees view the immediate supervisor as competent they would feel more confident that they could depend on him or her to help them out when they encounter job related impediments. Previous research has established that supervisory coaching in the form of assisting employees in locating their goals, organizing their work, highlighting drawbacks, taking a keen interest in their professional and career advancement, and offering advice as needed, has been positively related to work engagement (Schaufeli and Salanova, 2007). Such sharing 
of information, provision of instruction and support can only be possible if the supervisor is well-informed about professional requirements, has an exhaustive knowledge about the company and is an excellent judge of issues pertaining to interpersonal and political concerns of the organisation (Mayer et. al., 1995). Thus it is suggested that employees' trust in the capability and proficiency of their immediate supervisor is likely to make them realise that they have the resources to successfully achieve their desired work goals. This should give them the confidence to exercise more effort in their work, which in turn may lead to greater work engagement (Schaufeli and Bakker, 2004).

The openness dimension entails that supervisors exchange ideas and information with employees without any inhibitions. For example, information in the form of constructive and positive feedback from supervisors not only helps employees to work more efficiently but also augments communication and understanding between supervisors and employees (Bakker and Demerouti, 2007). Appropriate feedback from supervisors cultivates learning and enhances job competence of employees. Such positive communication and understanding would result in greater intrinsic motivation and work engagement (Bakker and Demerouti, 2007).

Furthermore, employees are likely to be more engaged in their work when they feel that their supervisors are supportive and concerned about their welfare and interests. Supervisors who promote a helpful and encouraging work environment characteristically demonstrate a concern for employees' requirements and opinions, provide constructive feedback, encourage them to be vocal about their concerns, and develop and cultivate new skills to help resolve work related problems (May et. al., 2004). These positive attempts by the supervisors should augment feelings of psychological safety and promote learning, growth and development. It is realistic to assume that such an encouraging and productive work environment can play a pivotal role in breeding work engagement.

Finally, employees would be more motivated to work with greater vigour and dedication towards the completion of their job requirements once they realise that their supervisors are trustworthy and dependable. Such an attitude from the employees stems from the fact that the supervisors are responsible for all those decisions that will directly impact the employees' potential to attain their goals. These decisions include: evaluating performance, help with job responsibilities, training and career development, and providing recognition and rewards (Dirks and Ferrin, 2002). Employees can easily digress into a state of psychological distress if they feel that they do not have faith in the leader to make fair and impartial decisions with regards to these aspects of the job. Such a digression could then lead to disengagement from work.

However, if the employees have full faith in their supervisors to show impartiality in their dealings with the employees and to fully acknowledge their efforts by providing suitable rewards and recognition, they are likely to devote all their energies to role performance and would subsequently be more positively engaged in their work.

As an amalgamation of the above discussion it is proposed that high trust in the immediate supervisor is expected to positively contribute towards increasing work engagement. 
Proposition 2: High trust in immediate supervisor at Time 1 would increase employees' work engagement at Time 2.

\section{Work Engagement and Trust in Co-workers}

It is proposed that a high level of trust in one's co-workers can also positively contribute to employees' work engagement. For example, employees would be confident about their co-workers' ability to provide work-related help, if the coworkers are proficient and knowledgeable about the job. This perception and ensuing confidence should help augment the work motivation of employees by fortifying their effort-performance expectancy, and as a consequence may lead to greater work engagement.

Competence and proficiency of co-workers achieves more significance when employees are working in teams and are extremely reliant on each other to accomplish their job responsibilities. According to Dirks (1999) when an individual believes that his group members lack the necessary abilities and skills, he may recognize his effort and hard work as unrelated to group performance. This is because such shortcomings will limit the performance of the group and as a result render his or her efforts futile. In such cases the individual is most likely to exercise a low level of effort (Dirks, 1999). A minuscule level of effort and commitment on part of the employee may lead to disengagement from work.

Additionally high trust in terms of the openness dimension is likely to give confidence to employees to share vital information with each other. Such a high level of trust would develop since the employees would feel more confident that their co-workers would not misuse the information shared. The presence of this vital, shared information can facilitate task completion and as a result may lead to greater work engagement (Hakanen et. al., 2006).

The concern dimension is also likely to positively impact work engagement. Employees will show higher levels of work engagement if they realize that their coworkers are sympathetic and concerned about their welfare and interests. Enhanced levels of trust, psychological safety and work engagement develop more readily in an environment where co-workers support each other during rough times at work, show concern and mutual respect for one another, and respect each other's contributions (May et. al., 2004). Furthermore, such kind of support and encouragement provides employees with the feelings of being accepted, respected and cared for, and as a result satisfies their need to belong. The fulfillment of the basic human need to belong, according to the self-determination theory (Deci and Ryan, 1985), should heighten intrinsic motivation, individual well being and consequently work engagement.

Finally, through the reliability dimension the employees believe that their co-workers would do what they say they will do. In such a situation it is speculated that the employees would remain focused on achieving their fundamental work objectives as opposed to expending their energies and resources on monitoring the behaviours and actions of their peers. Undivided attention on role performance, in turn, is likely to convert into higher work engagement. 
Proposition 3: High trust in co-workers at Time 1 would increase employees' work engagement at Time 2.

\section{The Relationship between Trust Propensity and Work Engagement}

This paper also proposes that trust propensity or trait trust would induce work engagement. Those people who typically trust others are more likely to engage in pro-social and cooperative behaviors even under uncertain and ambiguous circumstances because such individuals feel confident that they will be fairly treated and that eventually their good deeds and actions will be reciprocated in some manner (Van Dyne, VandeWalle, Kostova, Latham and Cummings, 2000). For instance, Van Dyne et. al. (2000) and Colquitt, Scott and LePine (2007) in their respective studies empirically demonstrate that 'high trustors' engage in more organizational citizenship behaviors. Furthermore, Rotter (1980) reports that people with a high propensity to trust are less likely to lie, cheat or steal and they are more likely to respect the rights of others, are liked by others and are sought out as friends. Moreover, high trustors tend to be less critical of others and are usually more forgiving of their mistakes (McKnight and Chervany, 2001). Indeed Colquitt et. al. in their meta-analytic study reveal that trust propensity is negatively related to counter productive behaviors. However, the positive outcomes of trust propensity should not be confused with the 'acting' behaviors suggested in the emotional labor or impression management literature. For instance, employees are said to engage in emotional labor when they convey socially desired emotions as part of their job role (Hochschild, 1979). In other words, it is the organizationally based expectations or 'display' rules that specify either formally or informally which emotions employees ought to communicate and which ought to be concealed (Mann, 2005). High trustors, however, do not demonstrate positive behaviors and emotions because they are bound to do so by organizationally based expectations. They do so because they are naturally inclined to engage in positive behaviors and actions.

Because of their positive attributes, it is argued that trusting individuals are likely to develop more effective and meaningful relationships with their supervisors and coworkers (Van Dyne et. al., 2000). This in turn should enable the high trusting individuals to build a more extensive social network which could facilitate them to mobilize resources (e.g. social support from co-workers and supervisors, performance feedback etc.) necessary for bolstering their engagement levels.

In addition, trusting individuals are less suspicious and less concerned about monitoring the behavior of others (Van Dyne et. al., 2000). This implies that such individuals will be able to focus their full attention on job tasks as opposed to diverting energy to monitoring and engaging in "self-preserving activities" (Mayer and Gavin, 2005). Full focus and concentration on work activities in turn should lead to greater work engagement (May et. al., 2004).

Proposition 4: High trust propensity at Time 1 would increase employees' work engagement at Time 2.

\section{Path from Work Engagement to Trust}


The above discussion implies that high levels of both state and trait trust at Time 1 will positively affect the engagement levels of employees at Time 2 . The second part of the proposed model argues that an increase in work engagement at Time 2 in turn would bolster the three situational forms of trust by positively affecting employees' propensity to trust at Time 3 . Although trust propensity is a relatively stable personality characteristic, it can be influenced by factors such as personality, experiences and culture (Schoorman, Mayer and Davis, 2007). For instance, Huff and Kelley (2003) argue that one's propensity to trust others can be affected by national culture. More specifically, they found that organizational members working in organizations from collectivist cultures had a lower propensity to trust others than employees from individualistic cultures. Thus it is predicted that trust propensity or trait trust will mediate the relationship between work engagement and the three types of state trust, namely, trust in top management, trust in immediate supervisor and trust in co-workers. First we would examine the relationship between work engagement and trust propensity and then analyse the mediating role of trust propensity in the engagement - state trust relationship.

\section{Relationship between Work Engagement and Trust Propensity}

It is posited that positive affect in the form of work engagement would positively influence one's propensity to trust. Research evidence indicates that when people are experiencing positive moods and emotions they are likely to develop more favourable attitudes towards other individuals which in turn may positively affect their willingness to trust other people (Williams, 2001; Jones and George, 1998). Work engagement is a positive psychological state and reflects a positive state of mind (Llorens, Schaufeli, Bakker and Salanova, 2007). Contrary to other psychological states such as the critical psychological states in the job characteristics model (Hackman and Oldham, 1980) which are purely cognitive in nature, engagement is "also an affective state" (Salanova and Schaufeli, 2008, p. 128). It is characterized by feelings such as optimism, energy, enthusiasm, pride and challenge (Bakker, Emmerik and Euwema, 2006). Thus it is speculated that when people are experiencing a positive state of mind in the form of work engagement, 'they may develop more positive perceptions of others and see the world through 'rose coloured glasses', resulting in a heightened experience of trust in another person' (Jones and George, 1998, p. 534). Dunn and Shcweitzer (2005) in their study empirically demonstrate that emotions with positive valence such as happiness and gratitude increase trust. Engagement is also a positive emotional state like happiness and gratitude. In fact, Peterson, Park and Seligman (2005) conceptualize engagement, together with meaning and pleasure, as a basic orientation to happiness. Thus it is predicted that work engagement may also positively affect an individual's tendency to trust by developing positive expectations about others.

Proposition 5: Work engagement at Time 2 positively relates to employees' trust propensity at Time 3 .

\section{Mediation of Work Engagement - State Trust Relationship}

The above discussion suggests that positive affect in the form of work engagement will heighten an individual's tendency to trust others. In turn it is expected that trust propensity would bolster the three situational forms of trust, that is, trust in top management, trust in immediate supervisor and trust in co-workers. 
For instance, Mayer et. al. (1995), argue that trust propensity, a stable "general willingness to trust others", increases trust "prior to availability of information about the trustee" (1995, p. 716). In a related vein, McKnight et. al. (1998) argue that the two components of their disposition to trust concept - faith in humanity and trusting stance are likely to positively affect trusting beliefs and trusting intentions in novel and ambiguous situations. Several studies have also empirically proved that trust propensity is an important precursor of state trust (Ridings, Gefen and Arinze, 2002; Payne and Clark, 2003; Mooradian et. al., 2006; Colquitt et. al., 2007).

However, an interesting question is that does trust propensity continue to influence state trust once trustworthiness of specific foci has been determined. Colquitt et. al. (2007) in their meta-analytic study argue that trust propensity may be an important determinant of trust even when information on trustworthiness has been ascertained. In fact, they empirically demonstrate that trust propensity remained a significant predictor of trust even when the three trustworthiness factors, namely, ability, benevolence and integrity were considered simultaneously. These findings further endorse trust propensity as an important determinant of state trust.

In light of the above discussion the following two propositions are proposed:

Proposition 6a: Trust propensity (Time 3) is positively related to the three forms of state trust (Time 3), namely, trust in top management, trust in immediate supervisor and trust in co-workers.

Proposition 6b: Trust propensity (Time 3) would mediate the relationship between work engagement (Time 2) and three forms of state trust (Time 3 ).

\section{Interaction Effects of State and Trait Trust on Work Engagement}

In addition to the main effects of state and trait trust, this study proposes that trait trust can interact with state trust to affect the engagement levels of employees. More specifically, it is posited that the positive relationship between the three forms of state trust and work engagement would be stronger if an individual's propensity to trust is high. As mentioned above, Colquitt et. al. (2007) empirically prove that trust propensity is likely to be a strong determinant of situational trust even after the information on trustworthiness of a particular foci has been acquired. Lewis and Weigert (1985) also argue on the same lines. More specifically, these scholars contend that trustworthiness:

"only opens the door to trust without actually constituting it. The cognitive element in trust is characterized by a cognitive 'leap' beyond the expectations that reason and experience alone would warrant - they simply serve as the platform from which the leap is made" (p. 971).

Thus it follows that even when employees have gathered data on the trustworthiness of their leaders and co-workers, they still may not be willing to be vulnerable to them if their general propensity to trust others is low. Therefore it is plausible that a low propensity to trust others may mitigate the positive effects of trust in top 
management, trust in supervisor and trust in co-workers on employees' work engagement. Thus the following proposition is proposed:

Proposition 7: The three forms of state trust and trait trust will interact with each other, such that the positive relationship between the three forms of state trust and work engagement will be stronger if trait trust or one's propensity to trust is high.

The above discussion is depicted by figure 2 below:

Figure 2. The Interaction Effects of State and Trait Trust on Work Engagement

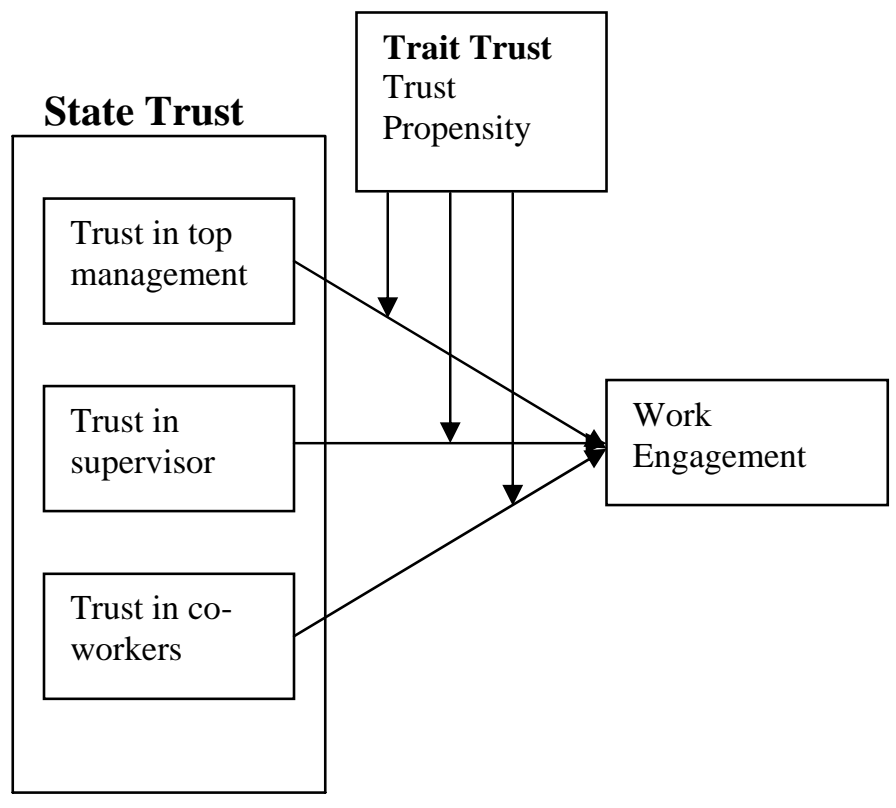

\section{Discussion}

Research on work engagement to-date has primarily expressed this construct as a function of job resources. The current paper extends the engagement literature by analysing how the two forms of trust, that is, state trust and trait trust and work engagement can affect each other. The model presented in this study suggests two paths. The first path proposes that high trust in top management, immediate supervisor and co-workers in terms of the four factors of trustworthiness (competence, openness, concern and reliability) specified by Mishra (1996) and a high propensity to trust others can enhance work engagement. It is argued that both state and trait trust can induce work engagement via two mechanisms.

First, both forms of trust can promote work engagement by allowing employees to concentrate on the work that needs to be done (Mayer and Gavin, 2005). For instance when employees lack trust in organizational leadership (i.e. the top management and immediate supervisor) and their co-workers - that is they are unwilling to be vulnerable to these foci - "their cognitive resources will be preoccupied with non- productive issues, especially activities focused on self protection 
or defensive behaviours" (Mayer and Gavin, 2005, p. 876). As a consequence employees would devote less attention to their work and would be less involved psychologically while performing their job tasks, which may lead to disengagement from work (Kahn, 1990; Rothbard, 2001; May et. al., 2004, Saks, 2006). In a related vein, employees who have a low propensity to trust others would be more suspicious of others and as a result are likely to spend a substantial portion of their time and energy on monitoring the behaviours and actions of others, which again may adversely impact their engagement levels.

Second, employees working in a climate of trust are likely to perceive more resources in their work environment, which would drive them to be more engaged in their work. For example, when employees believe that their supervisor and coworkers are competent they feel confident that they can rely on their supervisor and co-workers to provide instrumental help when they encounter job related problems (Costigan, Ilter and Berman, 1998). In such a situation employees are likely to perceive that they have the resources to complete their tasks successfully and achieve their work goals which in turn may motivate them to approach their work with greater vigour, dedication and absorption. In a similar vein, through the concern dimension of trust the employees believe that their supervisor and co-workers will not take advantage of them because the supervisor and co-workers care about their interests. This kind of perceived support should make the employees feel more accepted within the organization and should fulfil their need to belong. According to the self-determination theory (Deci and Ryan, 1985) work contexts, which satisfy the basic human need to belong by providing resources such as social support, can augment work engagement (Schaufeli and Salanova, 2007).

On the other hand, people with a dispositional tendency to trust others are likely to engage in more cooperative and pro-social behaviours (Colquitt et. al., 2007; Van Dyne et. al., 2000). In addition, they are less likely to lie, cheat or steal and they are more likely to respect the rights of others (Rotter, 1980). Because of these characteristics high trustors should be able to develop more positive and meaningful relationships with their co-workers and supervisors and as a result they may gain access to resources such as co-worker and supervisory support, feedback etc. which may enhance their engagement levels.

Surprisingly no study has empirically or conceptually examined the relationship between engagement and trust to date. However, there is empirical evidence that trust positively affects other indicators of motivation such as job satisfaction, organizational citizenship behaviour and turnover intentions (Dirks and Ferrin, 2002). In addition, trust has been found to be a robust predictor of organizational commitment (Dirks and Ferrin, 2002) - a construct which has some conceptual similarity with work engagement (Roberts and Davenport, 2002). Since engagement is also an indicator of motivation and bears a conceptual resemblance with organizational commitment, it is speculated that trust can play an important role in cultivating work engagement.

The second path of the proposed model posits that high levels of work engagement will bolster the three situational forms of trust, namely, trust in top management, trust in immediate supervisor, and trust in co-workers by positively influencing one's propensity to trust. More specifically it is argued that positive affect in the form of 
work engagement would lead people to develop more favorable attitudes towards others which in turn may increase their willingness to trust other people (Jones and George, 1998; Williams, 2001). An increase in the propensity to trust others is likely to enhance state trust at all three levels of the organizational hierarchy. It has been both conceptually (Mayer et. al., 1995; McKnight et. al., 1998) and empirically (Payne \& Clark, 2003; Colquitt et. al., 2007) demonstrated that trait trust is an important precursor of state trust. It is worth mentioning here that there is empirical evidence to suggest that state trust can also be induced by personality characteristics other than trust propensity. For instance Martins (2002) in her study showed that the 'big five' personality aspects, namely, conscientiousness, agreeableness, emotional stability, resourcefulness and extraversion were positively related to employees' trust in their immediate supervisor. In a related vein, Lilly and Virick (2006) in their study demonstrate that work locus of control had a significant and positive relationship with organizational trust. These findings imply that personality traits can play a significant role in influencing one's willingness to be vulnerable to others.

Finally, it is proposed that in addition to having main effects, state and trait trust can interact with each to affect work engagement. More specifically, it is argued that even in the presence of trustworthiness information about the three foci of state trust, employees may not be willing to be vulnerable to them if they have a low propensity to trust others, which in turn could adversely affect their engagement levels. Thus it is predicted that the positive relationship between the three forms of state trust and work engagement would be stronger if an individual's propensity to trust is high.

\section{Practical Implications}

The conceptual model presented in this study can have important implications for the organizations. It is proposed that high trait and state trust can enable the organizations to reap the benefits of employee engagement such as increased organizational commitment, reduced turnover and absenteeism rates and higher performance (Schaufeli \& Salanova, 2007). On the contrary, lower levels of state and trait trust can lead to negative consequences such as fear, suspicion, low commitment, reduced job satisfaction and higher turnover and absenteeism rates (Mishra \& Morrisey, 1990). In addition, in a low trust work environment employees are likely to expend enormous amount of their time and energy on monitoring the actions of others and therefore are liable to loose focus on achieving their work goals (Dirks, 1999; Mayer \& Gavin, 2005). All these factors can have deleterious effects on employee's work engagement.

Given the fact that trust is likely to play an important role in fostering work engagement, the question is that how can trust be increased in organizations? The four factors of trustworthiness specified in the present study: competence, openness, concern and reliability provide four different ways for fostering state trust at each level of the organizational hierarchy. Through appropriate training and development strategies, firms can enhance the job related skills of top managers, supervisors and co-workers. Moreover, employees at each level of the organizational hierarchy can be trained to act in a more fair, open, ethical and benevolent manner. If the organizational members are able to improve their skills in these areas they would be 
able to foster a more supportive work environment which in turn can play a crucial role in nurturing work engagement.

Furthermore, effective personnel selection and screening strategies can enable the firms to identify those individuals who have a higher tendency to trust others (Mooradian et. al., 2006). Such individuals can decisively contribute to creating a climate of trust within organizations.

An important issue, however, is that what is the proper level of trust? Is more trust always better? Not necessarily. Several authors argue that high levels of trust can generate a 'blindness' that can lead to the exploitation and mistreatment of the trustor (Kramer, 1996; Wicks, Berman \& Jones, 1999). Furthermore, Erdem (2003) argues that extreme trust can give birth to risks for teams because it can result in groupthink phenomenon. He posits that too much trust in the team leader or in each other can result in a blind acceptance of the status quo, which consequently can lead to a less dynamic team. In a related vein, a recent study by Langfred (2004) suggests that too much trust in the context of self managing teams can be counter productive and argues that high trust can lead to a reluctance to peer monitor, which when combined with high individual autonomy, can adversely affect team performance.

Therefore, it is plausible that existence of too much trust may actually reduce the engagement levels of employees, through for example the creation of groupthink phenomena, which can stifle creativity and initiative (Erdem, 2003) and as a result may negatively affect work engagement. Thus it is suggested that the organizations should aim to maintain an optimal level of trust, which refers to the "golden mean" between excess and deficiency (Wicks, Berman \& Jones, 1999).

\section{Limitations and Future Research}

As with all studies there are limitations to this research. The main limitation of this study is that the propositions developed in this study need to be empirically tested in order to establish their validity. There is a possibility that the relationships developed in this study may not materialize. Thus future research in this area should attempt to empirically test the model developed in this study to see whether a mutually reinforcing relationship exists between work engagement and trust.

Although this paper focuses on the relationship between trust and work engagement, future research should also empirically test the impact of other personality (e.g. locus of control, goal orientation etc.), psychological (e.g. organizational identification) and situational variables (e.g. organizational justice) on work engagement to achieve a better perceptive of this concept.

\section{Conclusion}

In spite of these limitations, the present study should be seen as one of the first attempts to analyze the relationship between work engagement and trust. Fostering work engagement is a highly viable organizational goal because of its positive impact on important organizational outcomes. It is suggested that by developing a climate of trust within their respective organizations, organizational leaders can increase work 
engagement which in turn may further boost trust. Thus we hope that future studies would continue to investigate the role trust in different research contexts in the building of employees' work engagement.

\section{References}

Bakker, A.B. \& Demerouti, E. (2007). The Job Demands-Resources model: State of the art. Journal of Managerial Psychology, 22, 309-328.

Bakker, A.B., van Emmerik, H. \& Euwema, M.C. (2006). Crossover of burnout and engagement in work teams. Work and Occupations, 33, 464-489.

Bigley, G.A. \& Pearce, J.L. (1998). Straining for shared meaning in organization science: Problems of trust and distrust. Academy of Management Review, 23, 405-421.

Blau, P.M. (1964). Exchange and power in social life. New York: Wiley.

Butler, J.K. \& Cantrell, R.S. (1984). A behavioural decision theory approach to modelling dyadic trust in superiors and subordinates. Psychological Reports, 55, 19-28.

Clark, M.C. \& Payne, R.L. (1987). The nature and structure of workers trust in management. Journal of Organizational Behaviour, 18, 205-224.

Colquitt, J.A., Brent, S.A. \& LePine, J.A. (2007). Trust trustworthiness, and trust propensity: A Meta-Analytic test of their unique relationships with risk taking and job performance. Journal of Applied Psychology, 92, 909-927.

Costigan, R.D., Ilter, S.S. and Berman, J.J. (1998). A multi-dimensional study of trust in organizations. Journal of Managerial Issues, 10, 303-317.

Cummings, L.L. \& Bromily, P. (1996). The organizational trust inventory (OTI): development \& validation. In Kramer, R. and Tyler, T. (Eds), Trust in organizations, (pp. 302-330). Sage, Thousand Oaks, CA.

Deci, E.L. \& Ryan, R.M. (1985). Intrinsic motivation and self determination in human behavior. New York: Plenum Press.

Demerouti, E., Bakker, A.B., Nachreiner, F. \& Schaufeli, W.B. (2001). The job-demandsresources model of burnout. Journal of Applied Psychology, 86, 499-512.

Dietz, G. \& Den Hartog, D.N. (2006). Measuring trust inside organizations. Personnel Review, 35, 557-558.

Dirks, K.T. (1999). The effects of interpersonal trust on work group performance. Journal of Applied Psychology, 84, 445-455.

Dirks, K.T. (2000). Trust in leadership and team performance: Evidence from NCCA Basketball. Journal of Applied Psychology, 85, 1004-1012. 
Dirks, K.T. \& Ferrin, D.L. (2002). Trust in leadership: Meta-Analytic findings and implications for research and practice. Journal of Applied Psychology, 87, 611-628.

Dirks, K.T. \& Skarlicki, D.P. (2004). Trust in leaders: Existing research and emerging issues. In Kramer, R.M. and Cook, K.S. (Eds.), Trust and distrust in organizations: Dilemmas and approaches, Russell Sage Foundation, New York.

Dunn, J.R. \& Schweitzer, M.E. (2005). Feeling and believing: The influence of emotion on trust. Journal of Personality and Social Psychology, 88, 736-748.

Ellis, K. \& Shockley-Zalabak, P. (2001). Trust in top management and immediate supervisor: The relationship to satisfaction, perceived organizational effectiveness and information receiving. Communication Quarterly, 49, 382-398.

Erdem, F. (2003). Optimal trust and teamwork: from group think to team think. Work Study, 52, 229-233.

Freeney, Y. \& Tiernan, J. (2006). Employee engagement: An overview of the literature on the proposed antithesis of burnout. The Irish Journal of Psychology, 27, 130-141.

Hackman, J.R. \& Oldham, G.R. (1980). Work redesign, Reading. PA: Addison Wesley.

Hakanen, J.J., Bakker, A.B. \& Schaufeli, W.B. (2006). Burnout and work engagement among teachers. Journal of School Psychology, 43, 495-513.

Hochschild, A. (1979). Emotion work, feeling rules and social structure. American Journal of Sociology, 85, 551-75.

Huff, L. \& Kelley, L. (2003). Levels of organizational trust in individualist versus collectivist societies: A seven - nation study. Organization Science, 14, 81-90.

Jones, G.R. \& George, J.M. (1998). The experience and evolution of Trust: Implications for cooperation and teamwork. Academy of Management Review, 23, 531-546.

Kahn, W.A. (1990). Psychological conditions of personal engagement and disengagement at work. Academy of Management Journal, 33, 692-724.

Kramer, R.M. (1996). Divergent realities and convergent disappointments in the hierarchic relation: Trust and the intuitive auditor at work. In Kramer, R. and Tyler, T. (Eds), Trust in Organizations (pp. 261-287). Sage, Thousand Oaks, California, CA.

Kramer, R.M. (1999). Trust and distrust in organizations: Emerging perspectives, enduring questions. Annual Review of Psychology, 50, 569-598.

Lewis, J.D. \& Weigert, A. (1985). Trust as a social reality. Social Forces, 63, 967-985.

Langfred, C.W. (2004). Too much of a good thing? Negative effects of high trust and individual autonomy in self managing teams. Academy of Management Journal, 47, 385-399. 
Lewiciki, R.J., Tomlinson, E.C. \& Gillespie, N. (2006). Models of interpersonal trust development: Theoretical approaches, empirical evidence and future directions. Journal of Management, 32, 992-1022.

Lilly, J.D. \& Virick, M. (2006). The effect of personality on perceptions of justice. Journal of Managerial Psychology, 21, 438-458.

Llorens, S., Schaufeli, W.B., Bakker A.B. \& Salanova, M. (2007). Does a positive gain spiral of resources, efficacy beliefs and engagement exist? Computers in Human Behaviour, 23, 825-841.

Mann, S. (2005). A health-care model of emotional labour: An evaluation of the literature and development of a model. Journal of Health Organization and Management, 19, 304-317.

Martins, N. (2002). A model for managing trust. International Journal of Manpower, 23, 754-769.

Maslach, C. \& Leiter, M.P. (1997). The truth about burnout. San Francisco: Jossey Bass.

Maslach, C., Jackson, S.E., \& Leiter, M.P. (1996). Maslach Burnout Inventory. , Palo Alto: Consulting Psychologist Press.

Maslach, C., Schaufeli, W.B. \& Leiter, M.P. (2001). Job Burnout. Annual Review of Psychology, 52, 397-422.

May, D.R., Gilson, R.L. \& Harter, L.M. (2004). The psychological conditions of meaningfulness, safety and availability and the engagement of human spirit at work. Journal of Occupational and Organizational Psychology, 77, 11-37.

Mayer, R.C. \& Gavin, M.B. (2005). Trust in management and performance: Who minds the shop while the employees watch the boss? Academy of Management Journal, 48, 874-888.

Mayer, R.C., Davis, J.H. \& Schoorman, D. (1995). An integrative model of organizational trust. Academy of Management Review, 20, 709-734.

McAllister, D.J. (1995). Affect and cognition based trust as foundations for interpersonal cooperation in organizations. The Academy of Management Journal, 38, 24-59.

McCauley, D.P. \& Kuhnert, K.W. (1992). A theoretical review and empirical investigation of employee trust in management. Public Administration Quarterly, 16, 265-282.

McKnight, D.H. \& Chervany, N.L. (2001). What trust means in E-Commerce customer relationships: An interdisciplinary conceptual typology. International Journal of ECommerce, 6, 35-59.

McKnight, D.H., Cummings, L.L. \& Chervany, N.L. (1998). Initial trust formation in new organizational relationships. Academy of Management Review, 23, 473-490. 
Mishra, A.K. (1996). Organizational responses to crisis: the centrality of trust. In Kramer, R. and Tyler, T. (Eds), Trust in Organizations, Sage, Thousand Oaks, California, CA.

Mishra, A.K. \& Spreitzer, G.M. (1998). Explaining how survivors respond to downsizing: The roles of trust, empowerment, justice and work design. The Academy of Management Review, 23, 567-588.

Mishra, J. \& Morrisey, M.A. (1990). Trust in employee / employer relationships: A survey of West Michigan Managers. Public Personnel Management, 19, 443- 461.

Mooradian, T., Renzl, B. \& Matzler (2006). Who trusts? Personality, trust and knowledge sharing. Management Learning, 37, 523-540.

Payne, R.L. \& Clark, M.C. (2003). Dispositional and situational determinants of trust in two types of managers? International Journal of Human Resource Management, 14, 128-138.

Peterson, C., Park, N. \& Seligman, M.E.P., (2005). Orientations to happiness and life satisfaction: The full life versus the empty life. Journal of Happiness Studies, 6, 2541.

Ridings, C.M., Gefen, D. \& Arinze, B. (2002). Some antecedents and effects of trust in virtual communities. Journal of Strategic Information Systems, 11, 271-295.

Roberts, D.R. \& Davenport, T.O. (2002). Job engagement: Why it's important and how to improve it. Employee Relations Today, 30, 21-29.

Robinson, S.L. (1996). Trust and Breach of Psychological Contract. Administrative Science Quarterly, 41, 574-599.

Robinson, S.L. \& Rousseau, D.M. (1994). Violating the psychological contract: Not the exception but the norm. Journal of Organizational Behaviour, 15, 245-259.

Rothbard, N.P. (2001). Enriching or depleting? The dynamics of engagement in work and family role. Administrative Science Quarterly, 46, 655-684.

Rotter, J.B. (1980), "Interpersonal trust, trustworthiness and gullibility", American Psychologist, 35, 1-7.

Rousseau, D.M., Sitkin, S.B., Burt, R.S. \& Camerer, C. (1998). Not so different after all: A cross-discipline view of trust. The Academy of Management Review, 23, 393-404.

Saks, A.M. (2006). Antecedents and consequences of employee engagement. Journal of Managerial Psychology, 21, 600-619.

Salanova, M., Agut, S. \& Peiro, J.M. (2005). Linking organizational resources and work engagement to employee performance and customer loyalty: The mediating role service climate. Journal of Applied Psychology, 90, 1217-1227. 
Salanova, M. \& Schaufeli, W.B. (2008). Job resources, engagement and proactive behaviour. International Journal of Human Resource Management, 19, 116-131.

Schaufeli, W.B. \& Bakker, A.B. (2004). Job demands, job resources and their relationship with burnout and engagement: A multi-sample study. Journal of Organizational Behaviour, 25, 293-315.

Schaufeli, W.B. \& Salanova, M. (2007). Work engagement: An emerging psychological concept and its implications for organizations. In Gilliland, S.W., Steiner, D.D. and Skarlicki, D.P. (Eds), Research in social issues in management, (pp. 135-177). Information Age Publishers, Greenwich, CT.

Schaufeli, W.B., Salanova, M., Gonzalez-Roma, V. \& Bakker, A.B. (2002). The measurement of burnout and engagement: A confirmatory factor analytic approach. Journal of Happiness Studies, 3, 71-92.

Schaufeli, W.B., Taris, T.W. \& Van Rhenen, W. (2008). Workaholism, burnout and engagement: Three of a kind or three different kinds of employee well-being? Applied Psychology: An International Review, 57, 173-203.

Schoorman, F.D., Mayer, R.C. \& Davis, J.H. (2007). An integrated model of organizational trust: Past, present and future. Academy of Management Review, 32, 344-354.

Shockley-Zalabak, P., Ellis, K. \& Winograd, G. (2000). Organizational trust: What it means, why it matters. Organizational Development Journal, 18, 35-47.

Sliegman, M.E.P., \& Csikszentmihalyi, M. (2000). Positive Psychology: An introduction. American Psychologist, 55, 5-14.

Smith, J.B. \& Barclay, W.B. (1997). The effects of organizational differences and trust on the effectiveness of selling partner relationships. Journal of Marketing, 61, 3-21.

Spreitzer, G.M. (1996). Social structural characteristics of psychological empowerment. Academy of Management Journal, 39, 483-504.

Spreitzer, G.M. \& Mishra, A.K. (2002). To stay or to go: voluntary survivor turnover following an organizational downsizing. Journal of Organizational Behaviour, 23, 707-729.

Tschannen-Moran, M. \& Hoy, W. (2000). A multidisciplinary analysis of the nature, meaning and measurement of trust. Review of Educational Research, 70, 547-593.

Van Dyne, L., VandeWalle, D., Kostova, T., Latham, M.E. and Cummings, L.L. (2000). Collectivisim, propensity to trust and self-esteem as predictors of organizational citizenship in a non-work setting. Journal of Organizational Behaviour, 21, 3-23.

Wicks, A.C., Shawn, L.B. and Jones, T.M. (1999). The structure of optimal trust: Moral and Strategic implications. Academy of Management Review, 24, 99-116. 
Williams, M. (2001). In whom we trust: Group membership as an affective context for trust development. Academy of Management Review, 26, 377-396.

\section{Author's Note}

An earlier version of this paper was presented at the $8^{\text {th }}$ EURAM (European Academy of Management) conference held in Ljubljana, Slovenia, May, 2008. 